Revista Brasileira de Farmacognosia Brazilian Journal of Pharmacognosy 21(5): 850-855, Sep./Oct. 2011

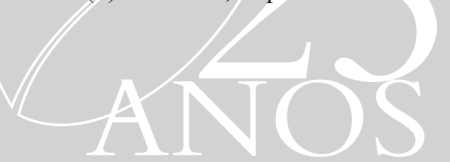

Article

Received 27 Dec 2010

Accepted 25 May 2011

Available online 12 Aug 2011

Keywords:

antimicrobial activity

Clinopodium nubigenum

essential oil

GC-MS

schizonepetoside

tipo de cerro

ISSN 0102-695X

http://dx.doi.org/10.1590/S0102-

695X2011005000139

\section{Phytochemical researches and antimicrobial activity of Clinopodium nubigenum Kunth (Kuntze) raw extracts}

\author{
Gianluca Gilardoni, ${ }^{1}$ Omar Malagon, ${ }^{4}$ Vladimir Morocho, ${ }^{4}$ \\ Riccardo Negri, ${ }^{1}$ Solveig Tosi, ${ }^{2,3}$ Maria Guglielminetti, ${ }^{3}$ Giovanni \\ Vidari, ${ }^{, 1,2}$ Paola Vita Finzi, ${ }^{1,2}$
}

\author{
${ }^{1}$ Università degli Studi di Pavia, Dipartimento di Chimica, Italia, \\ ${ }^{2}$ Università degli Studi di Pavia, Centro Interdipartimentale di Studi e Ricerche \\ sull'Etnobiofarmacia, Italia, \\ ${ }^{3}$ Università degli Studi di Pavia, Laboratorio di Micologia, Dipartimento di Scienze \\ della Terra e dell'Ambiente, Italia, \\ ${ }^{4}$ Universidad Técnica Particular de Loja, Instituto de Química Aplicada, Loja, Ecuador.
}

\begin{abstract}
The essential oil of the species Clinopodium nubigenum (Kunth) Kuntze, Lamiaceae, was analyzed by GC-MS and GC-FID, taking into account the more recent literature. Among the seventy compounds identified, the majority are oxygenated monoterpenoids. The essential oil, tested for antimicrobial activity, resulted effective in vitro against Candida albicans. From the aqueous $\mathrm{MeOH}$ extract of the aerial parts of the plant two nonvolatile compounds, named schizonepetoside $\mathrm{A}$ and schizonepedoside $\mathrm{C}$, have been isolated. They are rare glycosyl terpenoids, which were previously isolated from only one plant, but never found before in the genus Clinopodium.
\end{abstract}

Introduction

Clinopodium nubigenum (Kunth) Kuntze, an aromatic plant belonging to the family Lamiaceae, is also known with the synonymous Thymus nubigenus Kunth, Micromeria nubigena (Kunth) Benth, and Satureja nubigena (Kunth) Briq (Index Kewensis, 2010). It is widely growing in Latin America between 3000 and $4000 \mathrm{~m}$ a.s.1. The plant is popularly known by indigenous people as "tipo de cerro" and, in Ecuador, it is used as a traditional remedy by different communities. The Saraguro people use an aqueous infusion of the plant to treat colds (Andrade et al., 2009); in the region of Azuay, the plant is used as a remedy for flu (Rios et al., 2007); Quechua peoples in the High Sierra apply a decoction of $C$. nubigenum to cure stomach ache; Cañar communities use a plant infusion to avoid urinary incontinence in children; in Tungurahua, Chimborazo, Cañar, and Azuay provinces of Ecuador the plant finds applications also as a digestive, stomachic, a tonic remedy, and against dysentery and menstrual syndromes (de la Torre et al., 2008). Aromatic properties of $C$. nubigenum are due to the presence of an essential oil, easily obtainable by steam distillation, which has been analysed in this study. In addition, we examined the non volatile fraction of a $\mathrm{H}_{2} \mathrm{O}-\mathrm{MeOH}$ extract.

\section{Materials and Methods}

\section{Plant material}

The aerial parts of the plant were collected in January 2009, during the non-flowering period, at Aguarongo (3242 m a.s.l. coordinates 17700288E9585973N), in the San Lucas Parish, inside the Saraguro territory, Loja province, Ecuador. It has been identified by one of the authors (V. M.). A voucher sample is conserved at UTPL (Universitad Tecnica Particular de Loja), Loja, Ecuador, with the identification number PPN-la-018.

\section{Instruments and materials}

GC-MS analyses were performed on an Agilent Technologies $6890 \mathrm{~N}$ gas chromatograph, coupled with an Agilent Technologies 5973N (electronic impact source) System ATB-1550; GC-FID analyses were performed on a Perkin Elmer Auto System gas chromatograph; NMR spectra were determined in $\mathrm{MeOH}-\mathrm{d} 4$ obtained from Sigma-Aldrich; ACS solvents for extraction processes and HPLC grade solvents for chromatographic purifications were purchased from Carlo Erba Reagenti (Milan, Italy); C-18 reversed phase 
LiChroprep RP-18 $(25-40 \mu \mathrm{m})$ and silica gel Kieselgel 60 (230-400 mesh) were purchased from Merck.

\section{Essential oil distillation and analysis}

Two samples ( $200 \mathrm{~g}$ each) of air-dried and fresh aerial parts of the plant were separately hydrodistilled, producing two essential oils, A and B, respectively, spontaneously separating from the collected aqueous layers, with a yield of about $1 \% \mathrm{w} / \mathrm{w}$. The fresh plant batch was distilled in Loja (Ecuador) immediately after collection; the dry batch was distilled in Pavia (Italy) after four weeks.

The collected essential oils, after drying over anhydrous sodium sulfate, were clear, light yellow and mobile liquids, characterized by a pleasant, fresh and minty odor. Two samples $(1 \mu \mathrm{L})$ of a $5 \% \mathrm{v} / \mathrm{v}$ solution of each oil in dichloromethane were separately injected in GC-MS and analyzed under the same conditions, the second sample after addition to a mixture of $n$-alkane homologues from heptane to nonadecane. The latter hydrocarbon mixture served to calculate the Linear Retention Index (LRI) value of each oil constituent, according to Van Den Dool \& Kratz (1963).

The GC-MS instrument was equipped with a HP-5 capillary column (length: $30 \mathrm{~m}$, internal diameter: $0.25 \mathrm{~mm}$, thickness of the stationary phase: $0.25 \mu \mathrm{m}$ ); helium $(1 \mathrm{~mL} / \mathrm{min})$ was the carrier gas; the injector was operated in the split mode, with a split ratio of 19 and at the temperature of $250{ }^{\circ} \mathrm{C}$; the $\mathrm{GC}$ analysis was performed with the following oven temperature program: temperature initially kept at $60^{\circ} \mathrm{C}$ for $1 \mathrm{~min}$, then increased to $260{ }^{\circ} \mathrm{C}$ with a gradient rate of $5{ }^{\circ} \mathrm{C} /$ min, and kept at $260^{\circ} \mathrm{C}$ for an additional $10 \mathrm{~min}$. The MS spectra were acquired in the Scan Mode, with a $m / z$ range of 41-350 amu; solvent delay: 2 min.

The GC-FID instrument was equipped with a HP-5 capillary column (length: $25 \mathrm{~m}$, internal diameter: $0.25 \mathrm{~mm}$, thickness of the stationary phase: $0.25 \mu \mathrm{m}$ ), using nitrogen as the carrier gas at $1 \mathrm{~mL} / \mathrm{min}$; the injector was operated in the split mode, with a split ratio of 25 and at the temperature of $250^{\circ} \mathrm{C}$, detector temperature was set at $280^{\circ} \mathrm{C}$; the $\mathrm{GC}$ analysis was performed with the following oven temperature program: temperature initially kept at $60{ }^{\circ} \mathrm{C}$ for $1 \mathrm{~min}$, then increased to 200 ${ }^{\circ} \mathrm{C}$ with a gradient rate of $5{ }^{\circ} \mathrm{C} / \mathrm{min}$, then to $280^{\circ} \mathrm{C}$ with a gradient rate of $15{ }^{\circ} \mathrm{C} / \mathrm{min}$. and kept at $280^{\circ} \mathrm{C}$ for an additional 5 min.

\section{Solvent extraction and glycosides purification}

Dried aerial parts $(300 \mathrm{~g})$ were subjected to solvent extraction by maceration for $1 \mathrm{~h}$ at room temperature; the operation was repeated with three solvents of increasing polarity: $n$-hexane, $\mathrm{MeOH}, 90 \%$ aqueous $\mathrm{MeOH}$. After extraction, each mixture was filtered and the filtrates were separately evaporated under vacuum at $40{ }^{\circ} \mathrm{C}$ to afford three residues, weighing $3.6 \mathrm{~g}$ ( $n$-hexane), $16.0 \mathrm{~g}(\mathrm{MeOH})$, and 1.4 g $(90 \% \mathrm{MeOH})$, respectively. The last extract was subjected to preparative liquid chromatography on a C-18 column, eluted with an increasing gradient of $\mathrm{MeOH}$ in $\mathrm{H}_{2} \mathrm{O}$. Two fractions from this separation were further purified by preparative liquid chromatography on silica gel. Elution with an increasing gradient of $\mathrm{MeOH}$ in dichloromethane gave two pure glycosylated monoterpenoids. The compounds were identified by ${ }^{1} \mathrm{H}-\mathrm{NMR}$ and ${ }^{13} \mathrm{C}$-NMR spectroscopy, including DEPT and COSY experiments, as schizonepetoside A (1) and schizonepetoside C (2). The data were identical with those reported in the literature (Kubo et al., 1986; Lee et al., 2008).

\section{Biological assays}

The antimicrobial activity of essential oils $A$ and $B$ was evaluated against different species of bacteria (Bacillus subtilis ATCC 6633, Escherichia coli ATCC 10536, Staphylococcus aureus ATCC 6538) and fungi, isolated from patients (Candida albicans (C.P. Robin) Berkhout, Trichophyton mentagrophytes (C.P. Robin) Sabour.), and from environment (Aspergillus niger Tiegh. ATCC 16404 recently reclassified as Aspergillus brasiliensis Varga, Frisvad \& Samson). Tests were performed in triplicates based mainly on the CLSI procedures (NCCLS, 2006; 2008), with some modifications reported in this paragraph. Along the experiment, Luria Bertani and Sabouraud were used as culture media for bacteria and fungi, respectively; incubating temperatures was $37^{\circ} \mathrm{C}$ for C. albicans, $E$. coli and $S$. aureus, The other microorganisms were cultivated at $28{ }^{\circ} \mathrm{C}$. This temperature was chosen for $T$. mentagrophytes accordingly to Fernàndez-Torres et al. (2002). Controls were prepared with culture media or culture media with solvent.

Oil activity was at first qualitatively detected in Petri dishes $(140 \mathrm{~mm})$ by means of the agar diffusion method The mother suspensions were prepared from cultures growing on solid media $5 \mathrm{~cm}$ Petri dishes. Cultures of C. albicans, S. aureus, E. coli, and $B$. subtilis were $48 \mathrm{~h}$ old, while cultures of A. niger and T. mentagrophytes were 7 days old. For filamentous fungi, i.e. T. mentagrophytes and A. niger, presuspensions were prepared transferring part of the colony in a tube containing $\mathrm{NaCl} 0.85 \%$ water with broken cover slides and then stirred for $1 \mathrm{~min}$ by vortex. Inoculum suspensions were prepared transferring microorganisms in $2 \mathrm{~mL}$ sterile water with $0.85 \%$ $\mathrm{NaCl}$ (api bioMerieux) adjusted at $0.5 \mathrm{McF}$ arland by nephelometric measurement; $1 \mathrm{~mL}$ of the suspension 
for each microorganism was uniformly distributed on the agar surface of $9 \mathrm{~cm}$ Petri dishes. Results were recorded after 24 and $48 \mathrm{~h}$ for all the microorganisms, with the exception of $T$. mentagrophytes that was examined after five days. The activity of the oil against fungi and bacteria was evaluated by measuring the inhibition zone diameter using filter paper disks (diameter of $0.5 \mathrm{~cm}$ ) impregnated with $9 \mu \mathrm{L}$ of essential oil and $1 \mu \mathrm{L}$ of DMSO (Sigma-Aldrich). Penicillin $\mathrm{G} \mathrm{Na}$ salt and amphotericin B (both Sigma-Aldrich) were the reference compounds for bacteria and fungi, respectively. Minimum inhibitory concentration (MIC) was determined only for microorganisms which showed a inhibition halo $>1 \mathrm{~cm}$. Essential oil was added to liquid culture medium in 24 microwell plates at final concentration from 1.5 to $20 \mu \mathrm{L} / \mathrm{mL}$. Tween 80 $0.002 \%(\mathrm{v} / \mathrm{v})$ was included to enhance oil solubility. To determine the lowest concentration required to kill the test organism (minimum fungicidal or bactericidal concentration, MFC or MBC, respectively), the method described by Gadd (1986) was followed. The initial inoculum was subcultured from 24-48 h-old microwell plates contained the oil onto a fresh cultural medium free of the toxicant and examined after 24, 48, and 72 $h$, respectively.

\section{Results and Discussion}

The essential oil A, obtained from air-dried aerial parts of $C$. nubigenum, was mainly composed of monoterpenes and sesquiterpenes. Seventy components of this complex mixture were identified by comparison of their EI-MS spectra and calculated linear retention indexes (LRI) with recently reported data (Adams, 2007); the identity of compounds not listed in the reference text was established by means of Wiley and NIST electronic EI-MS libraries. The complete qualitative analysis is reported in Table 1, including compound percentage quantification by GC-FID and GC-MS peak integration. The composition determined for this essential oil corresponds to $97.6 \%$ and $88.7 \%$ of the entire GC-FID and GC-MS chromatogram, respectively; major compounds are pulegone, menthofuran, isopulegone, $\alpha$-copaene, zonarene, 1-octen-3-yl acetate, limonene, linalool, $p$-cymene, piperitenone, $\beta$-pinene, and 1,6-octadien-3,7-dimethyl3-ol.

The composition of the essential oil B, obtained by hydrodistillation of fresh aerial parts, resulted to be virtually identical to the other one, except for the relative amounts of menthofuran and isopulegone. In fact, $1.56 \%$ of isopulegone and $11.57 \%$ of an inseparable mixture of menthofuran and menthone were detected in the GC-FID of the oil A (Figure 1), with menthofuran largely prevailing (GC-MS), whereas menthofuran was almost absent in the oil B, with isopulegone occurring in a relatively high amount (Figure 2). The GC-MS comparison of the two essential oils A and B is shown in Figure 3. It is known that menthofuran biosynthesis proceeds from isopulegone through cytochrome P-450 dependent oxidation to 9-hydroxypulegone (Dewick, 2009; Mc Clanahan et al., 1988); isolation of the two glycosylated compounds $\mathbf{1}$ and $\mathbf{2}$ from $C$. nubigenum (vide infra) is a further proof of the pathway. Thus, some glucose cleavage from $\mathbf{1}$ and $\mathbf{2}$ probably occurred during the plant drying process, storage, and transport from Ecuador to Italy, explaining the differences between the two oils.

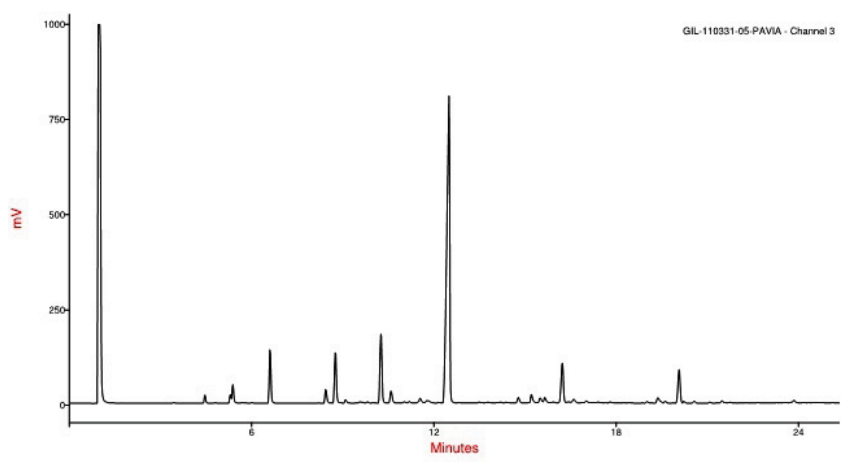

Figure 1. GC-FID analysis of the essential oil A from airdried aerial parts of C. nubigenum.

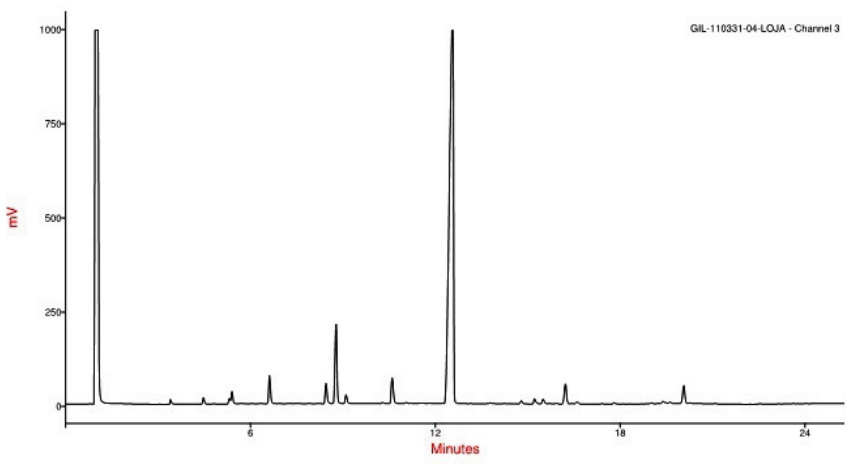

Figure 2. GC-FID analysis of the essential oil B from fresh aerial parts of C. nubigenum.

A few years ago, El Seedi and collaborators reported the essential oil analysis of Micromeria nubigena H.B.K. (El-Seedi et al., 2008). Interestingly, no plant appears with such authority in the Index Kewensis, contrary to the name Micromeria nubigena (Kunth) Benth, which is considered a synonymous of C. nubigenum Kunth (Kuntze) (Index Kewensis, 2010). The doubt thus exists that the two plants are different species. Indeed, comparison of our findings with the data reported by El Seedi clearly shows dramatic differences in the composition of the essential oils. For example, about $54 \%$ thymol and carvacrol were identified in the 
Table 1. Chemical analysis of the essential oil of C. nubigenum. LRI: Linear Retention Index (Van den Dool \& Kratz, 1963).

\begin{tabular}{|c|c|c|c|c|c|c|c|}
\hline COMPOUNDS & $\% \mathrm{~A}$ & $\% \mathrm{~B}$ & LRI & COMPOUNDS & $\% \mathrm{~A}$ & $\% \mathrm{~B}$ & LRI \\
\hline 1-Butanol-2-methyl acetate* & 0.01 & $<0.01$ & 876 & Isobornyl acetate & 0.1 & $<0.01$ & 1288 \\
\hline$\alpha$-Pinene & 0.85 & 0.45 & 934 & trans-Sabinyl acetate & 0.23 & 0.10 & 1294 \\
\hline Camphene & 0.12 & 0.03 & 949 & Nonanyl acetate & 0.18 & 0.02 & 1312 \\
\hline 3-Methyl-cyclohexanone & & & 951 & Myrtenyl acetate & 0.89 & 0.05 & 1328 \\
\hline Sabinene & 3.26 & 0.33 & 974 & Piperitenone & 1.52 & 0.34 & 1345 \\
\hline$\beta$-Pinene & & & 978 & Citronellyl acetate & 1.06 & 0.46 & 1355 \\
\hline 2-Pentyl furan & 0.11 & 0.06 & 992 & Eugenol & 1.11 & 0.51 & 1361 \\
\hline 3-Octanol & 0.11 & 0.04 & 996 & Piperitenone oxide & 0.21 & 0.11 & 1370 \\
\hline$p$-Mentha-1(7),8-diene & 0.05 & 0.03 & 1005 & $\alpha$-Copaene & 7.03 & 2.09 & 1381 \\
\hline Limonene & 6.46 & 2.07 & 1030 & trans-Myrtanol acetate & 0.22 & 0.08 & 1387 \\
\hline trans- $\beta$-Ocimene & 0.06 & 0.01 & 1048 & $\beta$-Bourbonene & 0.76 & 0.29 & 1389 \\
\hline$\gamma$-Terpinene & 0.01 & 0.01 & 1059 & $\beta$-Cubebene & & & 1393 \\
\hline$p$-Mentha-3,8-diene & 0.02 & 0.02 & 1071 & Elemene $<\beta$ - $>$ & 0.32 & $<0.01$ & 1395 \\
\hline Terpinolene & 0.09 & 0.01 & 1090 & (E)-Caryophyllene & 0.18 & 0.06 & 1423 \\
\hline$p$-Cymene & 2.08 & 1.73 & 1091 & $\beta$-Copaene & 0.50 & 0.16 & 1433 \\
\hline 1,6-Octadien-3-ol,3,7-dimethyl-* & 7.31 & 7.00 & 1101 & $\alpha$-Humulene & & & 1458 \\
\hline Linalool & 0.52 & 0.81 & 1101 & $\gamma$-Muurolene & 1.06 & 0.38 & 1480 \\
\hline Nonanal & 0.06 & 0.02 & 1105 & Germacrene D & & & 1485 \\
\hline 1-Octen-3-yl acetate & 0.46 & 0.02 & 1113 & $(E, E)$ - $\alpha$-Farnesene & 0.39 & 0.29 & 1510 \\
\hline 3-Octanol acetate & 0.25 & 0.02 & 1124 & Zonarene & 5.76 & 2.08 & 1529 \\
\hline$\alpha$-Campholenal & & & 1128 & $\alpha$-Calacorene & 0.41 & 0.05 & 1547 \\
\hline cis-Limonene oxide & & & 1135 & $\beta$-Calacorene & 0.57 & 0.05 & 1568 \\
\hline cis-p-Mentha-2,8-dien-1-ol & & & 1137 & $1 \alpha, 10 \alpha$-epoxy-Amorph-4-ene & 0.25 & 0.06 & 1576 \\
\hline$p$-Menth-3-en-8-ol & 0.14 & 0.01 & 1150 & $\beta$-Copaen-4- $\alpha$-ol $<\beta$-> & & & 1592 \\
\hline Menthone & 11.57 & 0.15 & 1156 & $\alpha$-Corocalene & 0.06 & 0.02 & 1629 \\
\hline Menthofuran & & & 1167 & Muurola-4,10(14)-dien-1- $\beta$-ol & 0.04 & 0.01 & 1635 \\
\hline cis-Isopulegone* & 1.56 & 4.74 & 1178 & $\alpha$-Muurolol & 0.02 & $<0.01$ & 1649 \\
\hline$\alpha$-Terpineol & 0.05 & 0.10 & 1194 & cis-Calamenen-10-ol & 0.08 & 0.06 & 1668 \\
\hline Decanal & 0.06 & 0.08 & 1207 & Cadalene & & & 1683 \\
\hline Acetic acid, non-3-enyl ester* & 0.80 & 0.13 & 1209 & Mostakone & 0.59 & 0.01 & 1687 \\
\hline Benzofuran-4,7-dimethyl* & 0.33 & 0.08 & 1216 & Amorpha-4,9-dien-2-ol & 0.26 & & 1705 \\
\hline Coahuilensol, methyl ether & 0.30 & 0.01 & 1226 & 10-nor-Calamenen-10-one & & & 1711 \\
\hline Pulegone* & 37.11 & 72.79 & 1249 & Pentadecanal* & & & 1718 \\
\hline Linalyl acetate & 0.05 & 0.01 & 1257 & Hexadecanal* & & & 1783 \\
\hline \multirow[t]{2}{*}{ Cinnamaldehyde $<(E)->$} & 0.03 & 0.02 & 1274 & 2-Pentadecanone,6,10,14-trimethyl-* & & & 1849 \\
\hline & & & & Tot. $\%$ & 97.59 & 98.09 & \\
\hline
\end{tabular}

A: from air-dried aerial parts. B: from fresh aerial parts. *Identified only by Wiley and NIST MS libraries.

hydrodistillate from M. nubigena H.B.K., while these phenols were not detected as significant components of the oils A and B in this study. In addition to species differences or the existence of botanical varieties, other factors, among which important are the climate, the soil, the harvest period and the vegetative cycle, and the method of plant and essential oil preservation, can explain the different chemical contents of the oils. Furthermore, it is worth noting that we collected the plant in the non-flowering period, while the previous essential oil was obtained by hydrodistillation of leaves and flowers (El-Seedi et al., 2008).

In addition to the essential oil, schizonepetoside $\mathrm{A}$ (1) and $\mathrm{C}$ (2) were isolated from the aqueous $\mathrm{MeOH}$ extract of the air-dried aerial parts of $C$. nubigenum. These compounds are rare glycosylated monoterpenoids, previously isolated, to the best of our knowledge, only from the plant Schizonepeta tenuifolia Briq. (Kubo et 
al., 1986; Lee et al., 2008), after which they have been named. They were identified by identical NMR data with those reported in the literature.

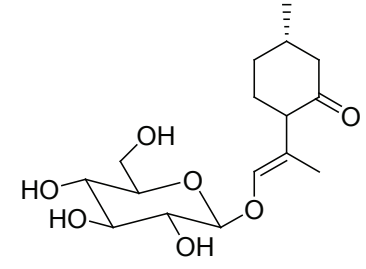

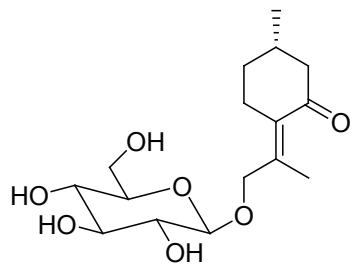

Table 2 shows the activity data of the $C$. nubigenum essential oils $\mathrm{A}$ and $\mathrm{B}$ against tested microorganisms. No differences between the replicate data were detectable to the naked eye. Difference between $\mathrm{A}$ and $\mathrm{B}$ was detectable only against $A$. niger after $24 \mathrm{~h}$ of incubation, but both oils showed no activity after $48 \mathrm{~h}$.
The most sensitive microorganism was $C$. albicans with a inhibition halo $>1 \mathrm{~cm}$. The MIC of the essential oils A and B against C. albicans are showed in Table 3. Fungicide activity (MFC) against the yeast was detected after $48 \mathrm{~h}$ treatment with a concentration of $8 \mu \mathrm{L} / \mathrm{mL}$ and $5 \mu \mathrm{L} / \mathrm{mL}$ for oil A and B, respectively. Interestingly, only fungistatic activity resulted after 24 $\mathrm{h}$ treatment.

The activity data reported in this paper are consistent with the antimicrobial activity shown by many genera and species belonging to the family Lamiaceae (De Martino et al., 2009). Antimicrobial properties of the genus Clinopodium were mainly investigated for Old World species. Most of them were demonstrated to be antimicrobial either against different bacteria or fungi (Stojanović et al., 2006; Castilho et al., 2007; Stojanović et al., 2009). Almost sixty species of the genus Clinopodium grow in tropical America (Harley, 2000), but biological activities of only few of them have been tested so far (El-Seedi et al., 2008; Estrada-Reyes et al., 2010). Antimicrobial activity of the

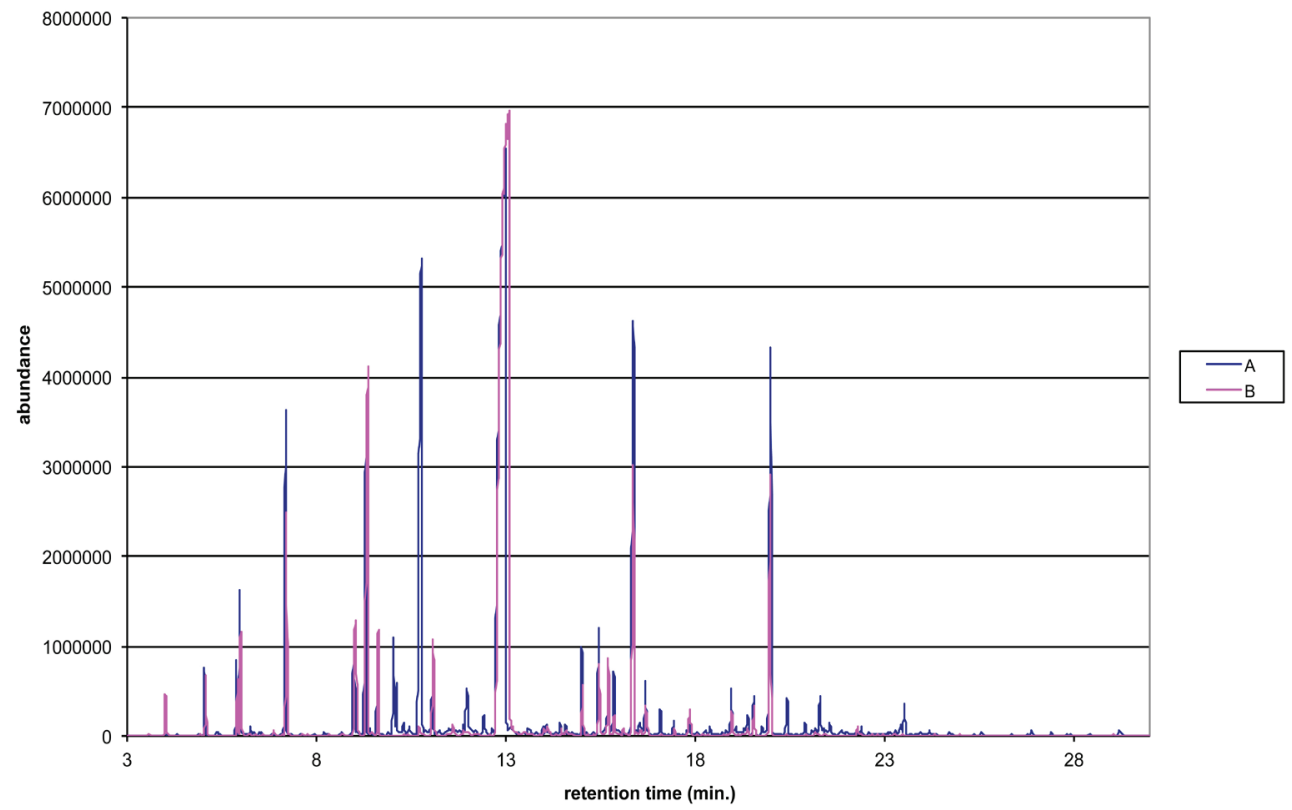

Figure 3. GC-MS comparison of the essential oil A, from air-dried aerial parts, with essential oil $\mathrm{B}$, from fresh aerial parts of $C$. nubigenum.

Table 2. Activity of the essential oils A and $\mathrm{B}$ of $C$. nubigenum against bacterial and fungal microorganisms, as shown by the inhibition zone diameter $(\mathrm{cm})$.

\begin{tabular}{lcccccc}
\hline \multirow{2}{*}{ Sample } & \multicolumn{3}{c}{ Fungi } & \multicolumn{2}{c}{ Bacteria } \\
\cline { 2 - 7 } & Aspergillus niger & $\begin{array}{c}\text { Candida } \\
\text { albicans }\end{array}$ & $\begin{array}{c}\text { Trichophyton } \\
\text { mentagrophytes }\end{array}$ & $\begin{array}{c}\text { Bacillus subtilis } \\
\text { Escherichia } \\
\text { coli }\end{array}$ & $\begin{array}{c}\text { Staphylococcus } \\
\text { aureus }\end{array}$ \\
\hline Essential oil A 9 $\mu \mathrm{L}$ & $\begin{array}{c}1.5 \text { after } 24 \mathrm{~h}, \\
0 \text { after } 48 \mathrm{~h}\end{array}$ & 1.2 & 0.6 & 0.7 & 0 & 0.8 \\
Essential oil B $9 \mu \mathrm{L}$ & $\begin{array}{c}2 \text { after } 24 \mathrm{~h}, \\
0 \text { after } 48 \mathrm{~h}\end{array}$ & 1.2 & 0.6 & 0.7 & 0 & 0.8 \\
Penicillin G Na salt $9 \mu \mathrm{g}$ & - & - & - & 2.4 & 2.7 & 2.7 \\
Amphotericin B 10 $10 \mathrm{~g}$ & 1.3 & 1.4 & 1.7 & - & - & 0 \\
\hline
\end{tabular}


essential oil of Micromeria nubigena H.B.K. was detected by El-Seedi et al. (2008), and data concerning C. albicans and $S$. aureus are comparable with those reported in this paper for $C$. nubigenum. In addition, we report for the first time the anticandidal MIC and MFC values of the essential oil, while demonstrating its fungicide activity. This result is very important for finding new remedy against $C$. albicans, which is the predominant species causing fungal infections

Table 3. Minimum Inhibitory Concentration (MIC) and Minimum Fungicidal Concentration (MFC) of the essential oils A and B from C. nubigenum.

\begin{tabular}{lcc}
\hline \multirow{2}{*}{ Sample } & \multicolumn{2}{c}{ Candida albicans } \\
\cline { 2 - 3 } & $\begin{array}{c}\text { MIC after } 24 \mathrm{~h} \\
\mu \mathrm{L} / \mathrm{mL}\end{array}$ & $\begin{array}{c}\text { MFC after } 48 \mathrm{~h} \\
\mu \mathrm{L} / \mathrm{mL}\end{array}$ \\
\hline Essential oil A & 8 & 8 \\
Essential oil B & 5 & 5 \\
Amphotericin B & 1 & und \\
\hline
\end{tabular}

Und: undetermined.

\section{Acknowledgment}

This article is dedicated to the memory of Riccardo Negri. We thank the Italian MIUR for financial support (Funds PRIN).

\section{References}

Adams R.P. 1995. Identification of essential oil components by mass chromatography/mass spectroscopy. Carol Stream, IL, USA: Allured Pub. Corp.

Adams RP 2007. Identification of Essential Oil Components by Gas Chromatography/Mass Spectrometry, $4^{\text {th }}$ ed. Carol Stream, IL, USA: Allured Pub. Corp.

Andrade JM, Armijos C, Malagón O, Lucero HY 2009. Plantas medicinales silvestres empleadas por la etnia Saraguro en la Parroquia San Lucas. Loja, Ecuador.

Castilho P, Liu K, Rodrigues AI, Feio S, Tomi F, Casanova J 2007. Composition and antimicrobial activity of the essential oil of Clinopodium ascendens (Jordan) Sampaio from Madeira. Flavour Fragr J 22: 139-144.

de la Torre L, Navarrete H, Muriel P, Macía M, Balslev H 2008. Enciclopedia de las Plantas Útiles de Ecuador. Quito \& Aarhus: Herbario QCA de la Escuela de Ciencias Biológicas de la Pontificia Universidad Católica del Ecuador \& Herbario AAU del Departamento de Ciencias Biológicas de la Universidad de Aarhus.

De Martino L, De Feo V, Nazzaro F 2009. Chemical composition and in vitro antimicrobial and mutagenic activities of seven Lamiaceae essential oils. Molecules 14: 42134230.

Dewick PM 2009. Medicinal Natural Products, a Biosynthetic Approach. $3^{\text {rd }}$ Ed. Chichester, West Susex, UK: John Wiley \& Sons, Ltd.

El-Seedi HR, Khattab A, Gaara AHM, Mohamed TK, Hassan NA, El-Kattan AE 2008. Essential oil analysis of Micromeria nubigena H.B.K. and its antimicrobial activity. $J$ Essent Oil Res 20: 452-456.

Estrada-Reyes R, Martínez-Vázquez M, Gallegos-Solís A, Heinze G, Moreno J 2010. Depressant effects of Clinopodium mexicanum Benth. Govaerts (Lamiaceae) on the central nervous system. J Ethnopharmacol 130: 1-8.

Fernàndez-Torres B, Cabanes FJ, Carrillo-Munoz AJ, Esteban A, Inza I, Abarca L, Guarro J 2002. Collaborative evaluation of optimal antifungal susceptibility testing condition for dermatophytes. J Clin Microbiol 40: 3999-4003.

Gadd GM 1986. Toxicity screening using fungi and yeast. In "Toxicity testing using microorganisms", vol. II, Dutka BJ \& Bitton G (Eds.), CRC Press, Florida: p. 43-77.

Harley RM, Paucer AG 2000. List of species of tropical American Clinopodium (Labiatae) with new combination. Kew Bulletin 55: 917-927.

Index Kewensis 2010. http://www.ipni.org/, access in autumn 2010.

Kubo M, Sasaki H, Endo T, Taguchi H, Yosioka I 1986. The constituents of Schizonepeta tenuifolia Briquet: Structure of a new monoterpene glucoside, schizonepetoside C. Chem Pharm Bull 34: 3097-3101.

Lee IK, Kim MA, Lee SY, Hong JK, Lee JH, Lee KR 2008. Phytochemical constituents of Schizonepeta tenuifolia Briquet. Nat Prod Sci 14: 100-106.

Mc Clanahan RH, Huitric AC, Pearson PG, Desper JC, Nelson SD 1988. Evidence for a Cytochrome P-450 catalyzed allylic rearrangement with double bond topomerization. J Am Chem Soc 110: 1979-1981.

NCCLS 2006. Methods for dilution antimicrobial susceptibility tests for bacteria that grow aerobically. Approved Standard - seventh edition: M7-A7. Wayne, PA, USA: Clinical and Laboratoty Standards Institute.

NCCLS 2008. Reference method for broth dilution antifungal susceptibility testing of yeasts; approved standards third edition: M27-A3. Wayne, PA, USA: Clinical and Laboratory Standards Institute.

Rios M, Koziol J, Brorgtoft Pedersen H \& Granda G (Eds) 2007. Plantas útiles del Ecuador: aplicaciones, retos y perspectivas. Quito, Ecuador: Ediciones Abya-Yala.

Stojanović G, Palić I, Ursić-Janković J 2006. Composition and antimicrobial activity of the essential oil of Micromeria cristata and Micromeria juliana. Flavour Fragr J 21: 7779.

Stojanović G, Golubović T, Kitić D, Palić R 2009. Acinos species: Chemical composition, antimicrobial and antioxidative activity. $J$ Med Plants Res 3: 1240-1247.

Van Den Dool H, Kratz PD 1963. A generalization of the retention index system including linear temperature programmed gas-liquid partition chromatography. J Chromatogr 11: 463-471.

\section{*Correspondence}

Giovanni Vidari

Università degli Studi di Pavia, Dipartimento di Chimica

via Taramelli 12, 27100 Pavia, Italia

vidari@unipv.it

Tel. +390382987322

Fax. +390382987323 